Cadernos de Clio, Curitiba, v. 9, nº 1, 2018

\title{
A CRÍTICA DE EMILY BRONTË EM O MORRO DOS VENTOS UIVANTES
}

\section{EMILY BRONTË'S CRITICS IN WUTHERING HEIGHTS}

Eduardo Gern Scoz ${ }^{1}$

Resumo: Este artigo é resultado de um trabalho escrito para a disciplina de História Contemporânea I e Teoria da História III, na Universidade Federal do Paraná (UFPR). Para a realização desse trabalho, cada aluno escolhia uma obra literária do século XIX para relacionar com os textos abordados nas duas disciplinas. Dessa forma, após ter escolhido o romance de Emily Brontë, $O$ Morro dos Ventos Uivantes, e reunido bibliografias complementares às das matérias mencionadas, pode-se ter uma análise interessante no tocante às áreas de gênero e crítica pós-colonial. Assim, o presente artigo reúne essas discussões de forma a entender que Brontë, sendo mulher em plena Revolução Industrial e colonialismo britânico, teceu importantes críticas a sua conjuntura e às formas de opressão que estavam presentes nesse contexto.

Palavras-chave: Literatura, Gênero, Pós-colonialismo, O Morro dos Ventos Uivantes.

Abstract: This article is the result of a work written for the discipline of Contemporary History I and History Theory III, at the Universidade Federal do Paraná (UFPR). To carry out this work, each student chose a nineteenth century literary work to relate to the texts addressed in both disciplines. Thus, having chosen Emily Brontë's novel, Wuthering Heights, and assembling complementary bibliographies from the aforementioned subjects, one can have an interesting analysis of gender and postcolonial criticism. Thus, this article brings together these discussions in order to

\footnotetext{
${ }^{1}$ Graduando em História (Licenciatura e Bacharelado) pela Universidade Federal do Paraná (UFPR). É bolsista do grupo PET História UFPR e faz Pesquisa Individual sob a orientação da $\operatorname{Prof}^{\mathrm{a}} \operatorname{Dr}^{\mathrm{a}}$ Ana Paula Vosne Martins.
} 
understand that Brontë, being a woman in the midst of the Industrial Revolution and British colonialism, made important criticisms of her conjuncture and the forms of oppression that were present in this context.

Keywords: Literature, Gender, Postcolonialism, Wuthering Heights.

\section{Introdução}

O Morro dos Ventos Uivantes foi publicado em 1848, na Inglaterra, pela escritora Emily Jane Brontë (1818-1848), com o título original Wuthering Heights. A autora nasceu na pequena cidade de Thornton, Yorkshire, Inglaterra e é irmã de duas outras importantes escritoras, Charlotte (1816-1855) e Anne (1820-1848). As irmãs são filhas do clérigo irlandês Patrick Brontë e de Maria Brontë, cuja morte após o parto de Anne fez com que elas fossem criadas em Howorth pelo pai e pela tia extremamente religiosa. Em decorrência da formação e da profissão do pai, as três tiveram educação formal - situação essa bastante diferente da maioria das meninas do período - as quais tinham acesso à biblioteca e conhecimentos variados, desde história à poesia.

O livro narra a trágica história de amor entre os protagonistas Catherine e Heathcliff Earnshaw. Em uma breve sinopse, para contextualizar os principais acontecimentos da narrativa, os quais serão importantes para as reflexões posteriores, a obra se inicia em 1801 e tem como foco a difícil relação de Heathcliff em sua nova casa. Ele foi adotado pelo Sr. Earnshaw, o que fez despertar a inveja e o ciúme de seu primogênito, Hindley, e a afeição de sua filha, Catherine. O amor entre os dois, Catherine e Heathcliff, não se desenvolve, pois ela se casa com Edgar 
Linton e morre ao dar à luz a sua filha, Catherine, deixando Heathcliff cego de amor e ódio. Dessa forma, toda essa difícil relação com sua família e consigo mesmo o faz dedicar o restante de sua vida para destruir Linton e se reencontrar com sua alma gêmea.

A obra não foi aclamada pelo público após seu lançamento por causa do cenário extremamente conservador que se observava na sociedade vitoriana da época (WASOWSKI, 2001: 6), adversa às retratações rústicas e agressivas de personagens e momentos no decorrer da escrita. Entretanto, atualmente é considerada uma das maiores obras primas da literatura inglesa, ao lado, inclusive, de obras das suas duas irmãs, como Jane Eyre e A senhora de Wildfell Hall. Brontë, infelizmente, não presenciou o sucesso do Morro dos Ventos Uivantes, pois faleceu de tuberculose um ano após a sua publicação. Contudo, é importante ressaltar que essas críticas conservadoras foram expostas pois os primeiros escritos de Charlotte, Emily e Anne foram publicados sob pseudônimos masculinos, Currer (Charlotte), Ellis (Emily) e Acton (Anne) Bell, uma vez que a escrita era reservada ao gênero masculino, enquanto os papéis femininos tradicionais desejados eram da esfera privada, do lar (TEODORESCU, 2007: 5).

Em um contexto de aceleradas mudanças sociais e econômicas na Europa, tendo a Inglaterra sido o berço da Revolução Industrial, com uma intensa vinda de camponeses em direção às cidades, Brontë se volta a escrever sobre uma realidade que estava aos poucos se esvaindo: o campo inglês. Ademais, os dois protagonistas da obra são sujeitos que a sociedade vitoriana marginalizava e silenciava, os imigrantes e as mulheres, 
Cadernos de Clio, Curitiba, v. 9, nº 1, 2018

principalmente devido ao pensamento de hegemonia e superioridade do homem branco britânico. Assim, Catherine, com sua personalidade forte e impetuosa, não correspondia à idealização de mulher do período - que deveria ser calma, piedosa e silenciosa - e Heathcliff é descrito como cigano, mesmo que em nenhuma parte da obra essa questão tenha sido esclarecida (WASOWSKI, 2001: 8). Dessa forma, influenciada pelas suas boas memórias e vivências nas pequenas cidades inglesas (TEODORESCU, 2007: 2), a autora privilegia esse cenário em contrapartida da maioria dos romances do período, que destacam a industrialização e a vida nas cidades. Assim, a classificação do romance de Brontë, como aponta Nancy Armstrong (2007: 89), é difícil de ser feita, por não se enquadrar nos moldes típicos dos romances do século XIX, os quais eram elogiosos aos clássicos humanistas.

Sendo assim, a escrita narrativa se torna uma relevante ferramenta para o entendimento do passado, utilizada como uma fonte para o historiador. François Hartog (2017), importante historiador francês, em sua obra Crer em história, disserta sobre as relações entre literatura e história no século XIX. Nesse período a História se tornou disciplina curricular e, com isso, tomou rumos cientificistas e metódicos, tendo como fontes os documentos oficiais e como tema a história política das nações e dos grandes homens. Assim, o romance surge como importante amostragem desse período em que a História não contemplava questões do dia a dia e da cultura - de forma geral. O Morro dos Ventos Uivantes atualmente é 
Cadernos de Clio, Curitiba, v. 9, nº 1, 2018

utilizado como subsídio para pesquisas historiográficas por ter em sua construção a preocupação com o retrato dessa época.

\section{Análise da obra $\boldsymbol{O}$ Morro dos Ventos Uivantes}

O historiador inglês Eric Hobsbawn em A Era das Revoluções (1977: 43-70) aponta que a Revolução Industrial transformou a sociedade e economia britânicas. Foi um período marcado por grande acumulação de capital por parte dos burgueses, mecanização do campo e com isso um expressivo êxodo rural em direção às cidades, movimento esse que empobrecia paulatinamente esses camponeses, que quando chegavam nas cidades, compunham o exército de trabalhadores fabris, imersos em condições insalubres e extensas jornadas de trabalho. Não obstante, essa situação não é a que se encontra na obra de Emily Brontë, mas sim uma Inglaterra dos campos, das pequenas vilas e dos costumes tradicionais desse povo. Esse cenário cria uma situação destoante desse romance para com os principais nomes do período, como de Charles Dickens, que retratou a sociedade europeia pós-industrialização, representando os vícios e as adversidades da vida na cidade grande.

Mesmo não se enquadrando nesse contexto de mudanças extensivas na sociedade britânica, Brontë não é uma mulher alienada de seu presente, muito menos desconhecedora de sua realidade. E isso é exemplificado nas 
particularidades das personagens principais da sua obra - um imigrante cigano e uma mulher -, na qual há forte realismo na retratação da violência, situação essa que, na análise de Lowy e Sayre (2015: 38-39), demonstra forte influência do romantismo. Nesse caso há uma semelhança com outras obras românticas, como de Eugène Sue, George Sand e de Honoré de Balzac, todos criticados pela forma como retratavam a sociedade, como a obra de Michelle Lima (2013: 35) aponta:

[...] caracterizavam o "povo" de forma degradante e impiedosa ao ressaltarem seus vícios e mazelas, diferindo de uma literatura anterior, de finais do século XVIII e princípios do XIX, que devia se afirmar, segundo alguns críticos, como instrumento de educação ou de "pedagogia" do cidadão.

Assim, Jules Michelet acreditava que os românticos viam arte no feio, acreditando que essas situações seriam exceções, não um retrato da sociedade. Já intelectuais como Harold Bloom (2007) inferem influência do Romantismo na escrita de Brontë, porém apontam para particularidades da obra que não se encaixam em categorias circunscritas. Bloom infere que as irmãs Brontë conceberam uma nova estética literária, influenciadas pela escrita do Lorde Byron e pela literatura gótica e dramática elisabetana, compondo o romance setentrional. Ademais, a autora foi inovadora ao tratar a relação da sociedade sendo descrita por um ponto de vista individual, como demonstra Juan Zhao (2011: 27) em seu artigo "Consciência feminina em O Morro dos Ventos Uivantes": 
O Morro dos Ventos Uivantes é diferente de qualquer outro romance no gênero da literatura vitoriana, pois está fora das tradições sociais de seu tempo. A literatura vitoriana caracteristicamente considera o indivíduo como um membro da sociedade. Em $O$ morro dos ventos uivantes, Emily Brontë descreve a sociedade de um ponto de vista totalmente individual pela primeira vez (Tradução livre) $)^{2}$.

Como infere a socióloga Adriana Teodorescu em sua obra The life and work of the Brontë sisters (2007), o campo é o local escolhido por Emily Brontë para ambientar sua obra. Por muito tempo essa questão foi respondida como sendo um alheamento pela Inglaterra de seu tempo, pois o cenário do Morro dos Ventos Uivantes era pertencente a uma Grã-Bretanha do passado, visto que as relações econômicas e sociais já não correspondiam ao descrito pela autora. Não obstante, as ciências sociais mais recentes apontam que esse distanciamento das cidades e da industrialização é advinda de uma crítica de Brontë ao seu período e à modernidade, pois em trechos da obra é descrita a pobreza das cidades e dos trabalhadores fabris, inclusive Heathcliff é adotado pelo Sr. Earnshaw pois estava abandonado nas ruas de Liverpool. Assim, é possível perceber que a autora é sutil em seu julgamento, porém demarca sua posição - não passadista - mas de crítica de seu tempo, como exemplificado nesse excerto de Daise Lilian Fonseca Dias (2011: 127):

2 "Wuthering Heights is unlike any other novel in the genre of Victorian literature in that it stands outside the social traditions of its time. Victorian literature characteristically regards the individual as a member of society. In Wuthering Heights, Emily Bronte describes the society from a completely individual point of view for the first time." 
Em O morro dos ventos uivantes, Brontë cria uma história que, aparentemente, denuncia os desdobramentos de figuras coloniais na Inglaterra, contudo, sua técnica de narrar ironiza a postura preconceituosa dos personagens ingleses que são utilizados pela voz narrativa para denunciar a opressão imposta ao estrangeiro de uma raça escura.

Dessa forma, percebe-se a relação de subversão dos papéis esperados de imigrantes e de mulheres, pois são eles que protagonizam a obra, fazendo com que os personagens ingleses do sexo masculino sejam secundários e, muitas vezes, subalternos a esses.

Nesse sentido, Brontë assemelha-se à produção pós-colonial do século XX, utilizando-se da escrita romântica e de elementos comuns na literatura - como a escrita em forma de diário de viagem - para trazer elementos que enalteceriam e validariam a cultura inglesa, para os criticar profundamente. A exemplo de quando torna o subalterno estrangeiro senhor de terras inglesas, situação essa não usual e não correspondente aos ideais que estavam formando a nacionalidade inglesa nesse contexto de imperialismo do século XIX, como aponta Daise Lilian Fonseca Dias (2011: 202):

O primeiro comentário de Heathcliff no livro - sobre aquela propriedade que havia sido (símbolo do poder e superioridade) dos Linton -, feito a Lockwood, é curto e decisivo: "Thrushcross Grange [...] é propriedade minha [...]. Entre". Essa é a primeira vez que o leitor o vê e ele está no portão de 
Cadernos de Clio, Curitiba, v. 9, $\mathrm{n}^{\circ} .1,2018$

entrada de O Morro dos Ventos Uivantes, exercitando seu direito de proprietário decidindo sobre quem entra.

Assim, percebe-se que os romances são espaços importantes para críticas a questões pertinentes da atualidade do autor ou da autora. As narrativas, alicerçando-se nos contextos próprios, lançam luz à espaços ou temáticas negligenciadas, transformando, a exemplo de Heathcliff, a superioridade branca britânica em algo não mais naturalizado em sua plenitude, mas sim em uma situação que pode - e aos olhos de Brontë, deve - mudar. Dessa forma, além da escrita de O Morro dos Ventos Uivantes, diversos outros escritores se dedicaram a temáticas literárias pós-coloniais, e no caso dos séculos XX e XXI, já baseados nos conceitos e críticas do pensamento pós-colonial. Como no caso da autora indiana Arundhati Roy, que se utiliza da escrita literária em sua obra $O$ deus das pequenas coisas (1997), para tratar de temas sensíveis como a misoginia, a discriminação racial, a sociedade de castas e a conturbada história política indiana.

O livro conta a história de uma família indiana na segunda metade do século 20, enfocando, principalmente, nas duas crianças gêmeas, Estha e Rahel, além de seus parentes. Imerso nesse contexto, Roy também emprega a teoria pós-colonial em sua abordagem em sintonia com os temas citados a pouco. Uma marca importante na obra de Roy é a forma como se dá atenção tanto a fatores bastante conhecidos como as castas, porém também a discriminações menos evidentes, como no caso dos casamentos entre religiões, além do desconforto de Rahel e Estha em diversas passagens da obra por serem apenas metade Hindus. Assim, percebe-se que essa escrita 
crítica não está presente apenas em Brontë, mas em diversos contextos, atuando como importante ferramenta de luta política.

Retomando a análise de O Morro dos Ventos Uivantes, é nítida a forma como a Inglaterra vitoriana construiu fortemente um discurso e uma prática sociopolítica de reclusão da mulher à esfera privada. Esse movimento cerceou a atuação delas na esfera pública, seja em qual fosse o meio, na indústria (onde recebiam salários menores e sofriam constantes agressões físicas, sexuais e morais) ou na política. Brontë constrói a protagonista Catherine Earnshaw afastada desse estereótipo, pois ela é descrita como uma mulher de personalidade forte e altiva, que não se deixa dobrar por ninguém, mesmo vivendo em um contexto tão repressivo às mulheres. Ela é descrita por alguns personagens como sendo uma “diabinha" e "alminha perversa! [...] sem dúvida uma pena justa para quem muito pecou aqui na terra!” (BRONTË, 2009: 48). Assim, percebe-se que Catherine vai na contramão do papel tradicional esperado para uma mulher abastada do campo inglês, causando estranheza e julgamento por parte de seus contemporâneos. A historiadora Michelle Perrot (2017: 130) descreve a produção historiográfica sobre esse contexto das mulheres na Europa do século XIX nesse trecho de sua obra Os excluídos da história:

A pesquisa feminista recente por vezes contribuiu para essa reavaliação do poder das mulheres. Em sua vontade de superar o discurso miserabilista da opressão, de subverter o ponto de vista da dominação, ela procurou mostrar a presença, a ação das mulheres, a plenitude dos seus papéis, e mesmo a coerência de sua "cultura" e a existência dos seus poderes. 
Esse excerto é importante pois mostra como a autora, em pleno século XIX, sendo uma mulher imersa em todas essas amarras e preconceitos, liberta sua protagonista desse padrão para uma maior agência dentro de sua vida pessoal e em família.

O século XIX foi palco de, como já mencionado, um recrudescimento considerável do cerceamento da atuação das mulheres na sociedade. Mas isso não impediu que diversas escritoras assumissem a escrita como ofício, desde Mary Wollstonecraft e sua filha Mary Shelley, às irmãs Brontë e à Jane Austen, além de muitas outras. Todas elas formularam respostas para esse contexto em que viviam através de suas personagens femininas - com exceção de Wollstonecraft, pois ela não escrevia romances, mas sim tratados filosóficos e políticos, como sua obra prima Reivindicação pelos direitos das mulheres, de 1792. Assim, essas respostas, mesmo sendo muito diversas, possuem muitos diálogos, como no caso das mulheres das obras de Jane Austen, sempre muito preocupadas com o casamento - sendo essa característica posteriormente analisada pelo movimento feminista como uma forma de crítica à situação difícil das mulheres -, como no caso de Elizabeth, em Orgulho e Preconceito, relutante desde o início da obra com a ideia do matrimônio. Mulher forte como a Catherine de Brontë, e com a característica de que mesmo casadas não se tornam submissas nem passivas.

Sendo assim, há em Catherine Earnshaw uma mulher que desafia os padrões impostos a ela, mesmo quando encarna papéis que são tradicionais, 
como de filha, esposa e mãe. Pois em partes da obra ela é descrita como desafiadora das ordens hierárquicas e de gênero, sabendo inclusive do poder e da força que exerce dentro do núcleo familiar, como exposto neste fragmento da obra:

\begin{abstract}
Nada lhe dava mais alegria do que nos ver todos ralhando ao mesmo tempo e ela nos desafiando com o seu olhar altivo e descarado e a resposta sempre na ponta da língua. Adorava ridicularizar os sermões do Joseph. A mim, atormentava constantemente a paciência. Quanto ao pai, fazia aquilo que ele mais detestava, ou seja, demonstrava como a sua pretensa insolência (que ele considerava real), tinha mais poder sobre Heathcliff do que a bondade dele (BRONTË: 144).
\end{abstract}

Heathcliff também estava distante dos ideais de homem britânico, a começar por ser imigrante e não ter, durante a obra, informações detalhadas sobre sua ascendência e história, sendo descrito como tendo pele mais escura e aparência de cigano. No decorrer da obra, o personagem é circunscrito por uma aura de agressividade e rancor, a qual é construída no decorrer da narrativa, fruto das intensas ofensas e opressões sofridas por ele por conta dos homens ingleses que o rodeiam, como descrito por Catherine nesse excerto de $O$ Morro dos Ventos Uivantes:

Diga-lhe o que Heathcliff é: uma criatura incorrigível, sem refinamento, sem cultura; um matagal de urze e pedra dura. Antes queria pôr aquele canarinho no parque, num dia de inverno, do que lhe recomendar que nutrisse qualquer sentimento por ele! Só uma deplorável ignorância do caráter 
Cadernos de Clio, Curitiba, v. 9, nº 1, 2018

de Heathcliff é que lhe pode meter esse sonho na cabeça. Por favor, não imagine que ele esconde um fundo de benevolência e afeto sob uma aparência severa! Ele não é um diamante bruto, uma ostra contendo, no seu interior, uma pérola... é um homem feroz e impiedoso (BRONTË, 2009: 141).

Dessa forma, Brontë desenvolve uma justificação, imbuída na crítica à superioridade racial e cultural britânica que a autora produz, que faz com que essa rusticidade de Heathcliff seja algo empático para com os leitores. Do mesmo modo que a rejeição do amor dele por Catherine causa a mesma sensação, pois ela não se liberta das amarras socioculturais de seu redor e casa com um homem rico, branco e inglês, Edgar Linton. Porém, como mencionado anteriormente, a grande virada do personagem e também ponto importante da trama e da crítica social presente na obra é a forma como ele supera todas essas questões e se torna um proprietário de terra com influência e dinheiro para se vingar dos que o oprimiram e o afastaram de sua amada (DIAS, 2011: 132), diferindo-se dos moldes que estavam traçados para um descendente de imigrantes na Inglaterra desse período.

Parte dessa crítica de Brontë está expressa na ascensão social de Heathcliff, pois há um movimento ambíguo nessa questão: ao mesmo tempo em que esse sucesso socioeconômico pode ser entendido como uma forma de contrapor os valores ingleses, ele também pode ser uma censura em relação ao acúmulo de capital. Desde os séculos XIII e XIV a burguesia vinha se consolidando nas cidades como classe mercantil e bancária cada vez mais importante. Entretanto a Revolução Industrial ampliou essa riqueza de forma exponencial, fazendo com que diversas correntes de 
Cadernos de Clio, Curitiba, v. 9, nº 1, 2018

pensamento do século XIX, muitas delas associadas ao Romantismo, criticassem esse cenário. Na obra $O$ Morro dos Ventos Uivantes essa questão pode ser vista na forma cada vez mais cruel e desumana que o protagonista assume no decorrer da história, mesmo tendo desde o começo uma personalidade difícil (LOWY e SAYRE, 2015: 35). Assim, como exemplificado pelo trecho a seguir da obra, Heathcliff assume um caráter doentio após a morte de Catherine, sendo então servo da vingança e da ambição:

E eu rezo uma oração... hei de repeti-la até que minha língua se entorpeça... Catherine Earnshaw, possas tu não encontrar sossego enquanto eu tiver vida! Dizes que te matei, persegue-me então! A vítima persegue seus matadores, creio eu. Sei que fantasmas têm vagado pela terra. Fica sempre comigo... encarna-te em qualquer forma... torna-me louco! Só não quero que me deixes neste abismo, onde não posso te encontrar! Oh, Deus! É inexprimível! Não posso viver sem minha vida! Não posso viver sem minha alma! (BRONTË, 2009: 39-40).

Outra questão importante dentro da narrativa é a forma como ela é contada, o propósito que a autora dá ao livro para que a trama se desenrole: a qual é a chegada do Sr. Lockwood e a forma como a criada Nelly Dean conta a história do Morro dos Ventos Uivantes ao forasteiro. Desse modo, desenvolve-se uma forma de descrição que privilegia o passado, sendo assim, mais uma forma do Romantismo como influência para a escrita de Brontë. 
Por fim, a religião também figura entre os assuntos de destaque na obra, visto que a autora, desde cedo, teve contato profundo com a religião, seja na figura de seu pai ou de sua tia, ambos bastante religiosos. Na obra, Brontë tece críticas profundas à forma como alguns personagens encaram a fé de forma fanática, em especial o serviçal da casa dos Earnshaw, Joseph. $\mathrm{Na}$ qual não há intenções positivas ou empatia pelo próximo, mas uma rotina de rezas e liturgias que não implicam em reais mudanças ou melhoras na vida dos envolvidos e dos próximos. Situação que Brontë verificava no contato diário com sua tia Elisabeth Branwell.

\section{Conclusões}

Por conseguinte, é preciso resgatar a crítica literária, desde o lançamento de grandes clássicos como $O$ morro dos ventos uivantes, Frankenstein e Razão e Sensibilidade, todos de escritoras inglesas renomadas, para entender o papel das mulheres na literatura. Pois os três possuem particularidades que os fazem clássicos e por isso devem ser analisados cuidadosamente, porém por serem escritos por mulheres e trazerem questões dissonantes dos discursos hegemônicos da época obtiveram críticas desfavoráveis. Sendo assim, percebe-se que o esforço intelectual de Emily Brontë ao escrever sobre assuntos como a imigração, a independência das mulheres e criticar ideologias importantes britânicas sendo mulher é uma revolução.

Dessa forma, assim como Mary Wollstonecraft, a qual discutia filosófica e politicamente a par com intelectuais como Jean Jacques 
Rousseau, foi esquecida e difamada por décadas, ou a obra de Jane Austen, a qual foi entendida como conservadora por protagonizar o matrimônio e, por isso, rechaçada, Emily Brontë foi recuperada. E é a partir também de teorias da atualidade que percebemos como a autora estava comprometida com as questões sociais e políticas de seu período, criticando-os de forma sutil e engajada, da mesma forma que Austen o fez, transformando a constância com que falava do casamento em crítica às poucas opções que as mulheres inglesas tinham no século XIX.

\section{Bibliografia}

ARMSTRONG, Nancy. Emily Brontë In and Out of Her Time. In: BLOOM, Harold (org.). Bloom's Modern Critical Interpretations: Wuthering Heights, Updated Edition. Nova Iorque: Bloom's Literary Criticism, 2007, pp. 89-106.

BLOOM, Harold. Introduction. In: BLOOM, Harold (org.). Bloom's Modern Critical Interpretations: Wuthering Heights, Updated Edition. Nova Iorque: Bloom's Literary Criticism, 2007, pp. 1-8.

BRONTË, Emily. O Morro dos Ventos Uivantes. São Paulo: Lua de Papel, 2009.

DIAS, Daise Lilian Fonseca. A subversão das relações coloniais em O Morro dos Ventos Uivantes: questões de gênero. 2011. 282 f. Tese (Doutorado em Letras) - Programa de Pós-Graduação em Letras da Universidade Federal da Paraíba, Universidade Federal da Paraíba, João Pessoa, 2011.

HARTOG, F. História e Romance. In.: Crer em história. Belo Horizonte: Autêntica Editora, 2017. 
Cadernos de Clio, Curitiba, v. 9, nº 1, 2018

HOBSBAWM, Eric. A Era das Revoluções (1789-1848). Rio de Janeiro: Paz e Terra S.A. 1977.

LIMA, Michelle Schreiner. Jules Michelet (1795-1886). In. BENTIVOGLIO, Julio e LOPES, Marcos Antônio. A constituição da história como ciência. De Ranke a Braudel. Petrópolis: Vozes, 2013, pp. 33-58.

LOWY, Michael; SAYRE, Robert. Revolta e Melancolia: o romantismo na contracorrente da modernidade. São Paulo: Editora Boitempo, 2015, pp. 85-117.

PERROT, Michelle. Os excluídos da história: operários, mulheres e prisioneiros. São Paulo: Paz e Terra, 2017.

ROY, Arundhati. O deus das pequenas coisas. Trad. José Rubens Siqueira. São Paulo: Companhia das Letras, 1997.

TEODORESCU, Adriana. The life and the work of the Brontë sisters. Bucareste: Christian University, 2007.

WASOWSKI, Richard P. Introduction to the novel. In: Cliffs Notes Wuthering Heights. Hoboken: Wiley Publishing, Inc., 2001, pp. 6-8.

ZHAO, Juan. Female consciouness in Whutering Heights. Studies in Literature and Language. Quebec, vol. 3, no. 2, 2011, pp. 25-27.

Recebido em: 19/08/2019.

Aceito em: 24/01/2020. 